\title{
ANALISIS KINERJA PRODUKSI INSTALASI PENGOLAHAN AIR I PADA PERUSAHAAN DAERAH AIR MINUM (PDAM) BANDARMASIH DENGAN MENGGUNAKAN METODE OBJECTIVE MATRIX (OMAX)
}

\author{
Parhani $^{1}$, Muhammad Marsudi ${ }^{1}$, Idzani Muttaqin ${ }^{1}$ \\ Program Studi Teknik Industri, Fakultas Teknik \\ Universitas Islam Kalimantan Muhammad Arsyad Al Banjari Banjarmasin \\ Jl. Adhyaksa No 2 Kayu Tangi Banjarmasin 70123 Indonesia \\ e-mail:Farhan120493@gmail.com
}

\begin{abstract}
Abstrak-PDAM merupakan Badan usaha milik daerah yang termasuk dalam kategori pelayanan jasa dengan tugasnya memberikan pelayanan air bersih kepada masyarakat. Sebagai instansi pemerintahan yang bertanggung jawab untuk memberikan pelayanan masyarakat, maka untuk melihat kualitasnya dilihat dari proses kinerjanya dalam penyedia air bersih dalam produksi instalasi pengolahan air . Kinerja di sebuah perusahaan sangat penting dibutuhkan, terutama dalam Perusahaan Daerah Air Minum (PDAM) Bandarmasih pada bagian produksi instalasi pengolahan air. karena dengan adanya kinerja, Perusahaan dapat mengukur sejauh mana perkembangan usaha yang sudah dijalankan karyawan sesuai tanggung jawab masing.masing. Perumusan masalah dalam penelitian ini adalah bagaimana kinerja yang ada dalam Perusahaan Daerah Air Minum (PDAM) Bandarmasih pada bagian produksi Instalasi Pengolahan Air. Dalam penelitian ini yang menjadi objek penelitiannya adalah penggunaan metode Objective Matrix (OMAX) pada perhitungan bahan baku utama, bahan baku pendukung, tenaga kerja, jam kerja dan tenaga listrik pada Perusahaan Daerah Air Minum.
\end{abstract}

Kata kunci: Kinerja produksi, PDAM Bandarmasih, Metode Objective Matrix (OMAX).

\section{PENDAHULUAN}

A ir merupakan salah satu kebutuhan yang sangat vital dan mutlak diperlukan oleh semua makhluk hidup terutama manusia yang harus tersedia dalam hidup sehari-hari, baik untuk minum, mandi, mencuci dan sebagainya. Air merupakan kebutuhan yang sangat diharapkan oleh masyarakat untuk aktivitas sehari-hari. Dengan adanya Perusahaan Air Minum (PDAM) Bandarmasih yang dikelola oleh pemerintah daerah dengan harapan dapat melayani masyarakat dengan sebaik mungkin, khususnya masyarakat kota Banjarmasin. Dengan adanya penilaian kinerja dalam Perusahaan Air Minum (PDAM) Bandarmasih pada produksi Instalasi Pengolahan Air 1 manajemen dapat mengevaluasi atau menilai prestasi kinerja karyawan, sehingga kegiatan ini dapat memperbaiki keputusan- keputusan personalia dan memberikan umpan balik kepada para karyawan tentang pelaksanaan kinerja mereka dalam setiap tahunnya agar bisa diberi pertanggung jawaban terhadap perusahaan secara keseluruhan.

Kinerja di sebuah perusahaan sangat penting dibutuhkan, terutama dalam Perusahaan Daerah Air Minum (PDAM) Bandarmasih pada bagian produksi instalasi pengolahan air 1. karena dengan adanya kinerja, Perusahaan dapat mengukur sejauh mana perkembangan usaha yang sudah dijalankan karyawan sesuai tanggung jawab masing- masing. Mengukur kinerja pada

Perusahaan Daerah Air Minum (PDAM) Bandarmasih pada bagian Instalasi Pengolahan Air begitu penting untuk dilaksanakan agar bisa mendorong dalam kemajuan perusahaan selanjutnya. Dalam seiringnya waktu pasar global pasti akan menghadapi persaingan-persaingan, maka dari itu perusahaan harus selalu menigkatkan kinerja terus menerus. Salah satunya adalah dengan cara melakukan siklus kinerja dalam beberapa tahap, yaitu mengukur kinerja, mengevaluasi kinerja, meningkatkan kinerja dan merancanakan kinerja. Berdasarkan yang di uraikan di atas, penulis mempunyai ketertarikan untuk melakukan penelitian Tugas Akhir yaitu dengan menganalisis suatu kinerja yang ada di Perusahaan Daerah Air Minum (PDAM) Bandarmasih khususnya dibagian produksi IPA 1 agar menjadi kinerja yang lebih baik dari sekarang.

Dari permasalahan yang diuraikan di atas, penulis mengambil dengan judul, "ANALISIS KINERJA PRODUKSI IPA 1 PADA PERUSAHAAN DAERAH AIR MINUM (PDAM) BANDARMASIH DENGAN MENGGUNAKAN METODE OBJECTIVE MATRIX (OMAX)".

\section{METODE PENELITIAN}

Dalam penelitian ini yang menjadi objek penelitiannya adalah penggunaan metode Objective Matrix (OMAX) pada perhitungan bahan baku utama, bahan baku pendukung, tenaga kerja, jam kerja dan tenaga listrik pada Perusahaan Daerah Air Minum (PDAM) Bandarmasih. Berdasarkan objek penelitian tersebut, maka akan dianalisis bagaimana kinerja Objective Matrix (OMAX) dalam upaya meningkatkan produktivitas kinerja produksi 
Instalasi Pengolahan Air I (IPA I) pada Perusahaan Daerah Air Minum (PDAM) Bandarmasih.

Pada tahap pengumpulan data ini akan membahas tentang data-data yang digunakan yaitu data bahan baku utama, bahan baku pendukung, pemakaian tenaga kerja, efisiensi, energi dan efektifitas. Dalam mengumpulkan data dilakukan yaitu sebagai berikut :

a. Observasi

Observasi adalah mencari informasi-informasi yang dibutuhkan dengan mengamati atau memantau secara langsung ketempat lokasi penelitian yang mengarah tentang analisi kinerja, manajemen pada Perusahaan Daerah Air Minum (PDAM) Bandarmasih.

b. Wawancara (Interview)

Dalam mencari data penulis langsung terjun ke lapangan untuk berhadapan dengan Kepala bidang produksi (Bapak Alimansyah) untuk mendapatkan informasi-informasi yang ada dalam prusahaaan Daerah Air Minum (PDAM) Bandarmasih pada bagian produksi, penulis terlebih dahulu menyiapkan bahan-bahan daftar untuk wawancara agar lebih mempermudah untuk dipahami oleh pihak perusahaan.

\section{HASIL DAN PEMBAHASAN}

\section{A. Analisis Data}

Pada tahap ini akan membahas tentang data-data yang digunakan yaitu data hasil produksi, jumlah bahan baku utama, jumlah bahan baku pendukung, jumlah tenaga kerja, jumlah hari kerja, jumlah jam kerja, jumlah pemakaian energi listrik (kwh) dan jumlah output. Dalam mengumpulkan data dilakukan yaitu sebagai berikut:

1. Observasi

Observasi merupakan suatu proses penelitian dengan mengamati suatu kondisi dari bahan-bahan pengamatan dilapangan Perusahaan Daerah Air Minum (PDAM) Bandarmasih.

2. Wawancara

Wawancara merupakan suatu proses komunikasi dengan tujuan serius untuk bertukar pendapat maupun melibatkan tanya jawab secara langsung kepada pihak karyawan Perusahaan Daerah Air Minum (PDAM) Bandarmasih.

3. Pengolahan Data

Pengolahan data yang dilakukan dengan cara analisis dokumen pada bagian produksi dan laboratorium. kemudian hasil dari data analisis tersebut untuk mengatahui kondisi kinerja di lapangan yang ada dalam bagian produksi instalasi pengolahan air 1 . Setelah mengatahui kondisi kinerja di lapangan. data yang sudah didapat nantinya akan dibandingkan dengan data sekunder yang terdapat di Perusahaan Daerah Air Minum (PDAM) Bandarmasih. sehingga dapat dilihat hasil kinerja pada bagian produksi instalasi pengolahan air 1 di Perusahaan Daerah Air Minum (PDAM) Bandarmasih.

\section{Bahan Baku Utama}

Bahan baku utama merupakan bahan baku air sungai martapura yang di produksi untuk instalasi pengolahan air agar menghasilkan air bersih untuk dipakai oleh masyarakat khususnya masyarakat kota Banjarmasin. Produktivitas penggunaan bahan baku air sungai martpura dapat dihitung dengan rumus sebagai baerikut:

Rasio (1) =output (m3)bahan baku utama (m3) $x 100 \%$

\section{Bahan Baku Pendukung}

Bahan baku pendukung merupakan tawas untuk menghasilkan air. Produktivitas penggunaan bahan baku pendukung dapat dihitung dengan rumus sebagai baerikut : Rasio yang digunakan untuk menghitung bahan baku pendukung yaitu :

\section{Rasio (2) =Output (M3)B ahan Baku Pendukung(Kg)}

\section{Pemakaian Tenaga Kerja}

Tenaga kerja merupakan karyawan yang dipakai pada Perusahaan Daerah Air Minum (PDAM) Bandarmasih pada bagian produksi instalasi pengolahan air 1 sebanyak 14 Orang tenaga kerja. Produktivitas penggunaan tenaga kerja dapat dihitung dengan rumus sebagai baerikut : Rasio yang digunakan untuk menghitung bahan baku pendukung yaitu :

\section{Rasio (3) =OutputJumlah tenaga kerja $\left(\mathrm{m}^{3}\right) /$ orang}

\section{Jam Kerja (Efisiensi)}

Jam kerja merupakan jam yang dipakai oleh Perusahaan Daerah Air Minum (PDAM) Bandarmasih dibagian produksi instalasi pengolahan air I. Produktivitas penggunaan jam kerja dapat dihitung dengan rumus sebagai baerikut : Rasio yang digunakan untuk menghitung bahan baku pendukung yaitu :

\section{Rasio (4) =OutputJam kerja/bulan $M^{3} / J a m$}

\section{Energi Listrik (Kwh)}

Energi listrik merupakan energi yang dipakai untuk memproduksi bahan baku utama pada instalasi pengolahan air di Perusahaan Daerah Air Minum (PDAM) Bandarmasih. Perhitungan analisis dengan menggunakan rumus sebagai berikut

\section{Rasio (5) $=$ Output $\Sigma K w h M^{3} / K w h$}

\section{Efektifitas}

Efektifitas merupakan tujuan yang ingin dicapai pada Perusahaan Daerah Air Minum (PDAM) Bandarmasih dibagian produksi untuk memproduksi bahan baku utama. Perhitungan hasil analisis efektifitas dengan menggunakan rumus sebagai berikut:

\section{Rasio (6) =Bahan Baku Utama-OutputOutput X 100\%}

Pengukuran produktifitas standar atau rata-rata dari nilai rasio pada tahun 2019 dari bulan Januari sampai bulan Desember adalah menentukan nilai tahap awal. Matrix sasaran diletakkan pada tingkat ketiga. untuk menetukan nilai tahap awal yaitu dengan merata-rata nilai rasio pada tahun 2019 dari bulan Januari sampai dengan bulan Desember.

\section{B. Pembentukan Objective Matrix (Omax)}

Nilai-nilai dalam pembentukan matrix Omax adalah nilai tahap awal. nilai sasaran akhir. dan nilai terendah nilai bobot masing-masing rasio. Adapun Matrix Omax sasaran Perusahaan Daerah Air Minum (PDAM) 
Bandarmasih dapat dilihat pada tabel periode sebagai berikut:

\section{Evaluasi Hasil Objective Matrix (Omax)}

Berdasarkan hasil penilaian kinerja perusahaan yang dihitung menggunakan matrix Omax. PDAM
Bandarmasih memiliki skor penilaian rasio 1 hingga rasio 6 berkisar antara $4-6$ dengan kategori skor yaitu sedang - baik. Hasil penilaian skor aktual tiap rasio ditampilkan pada diagram 4.5 .1 berikut :

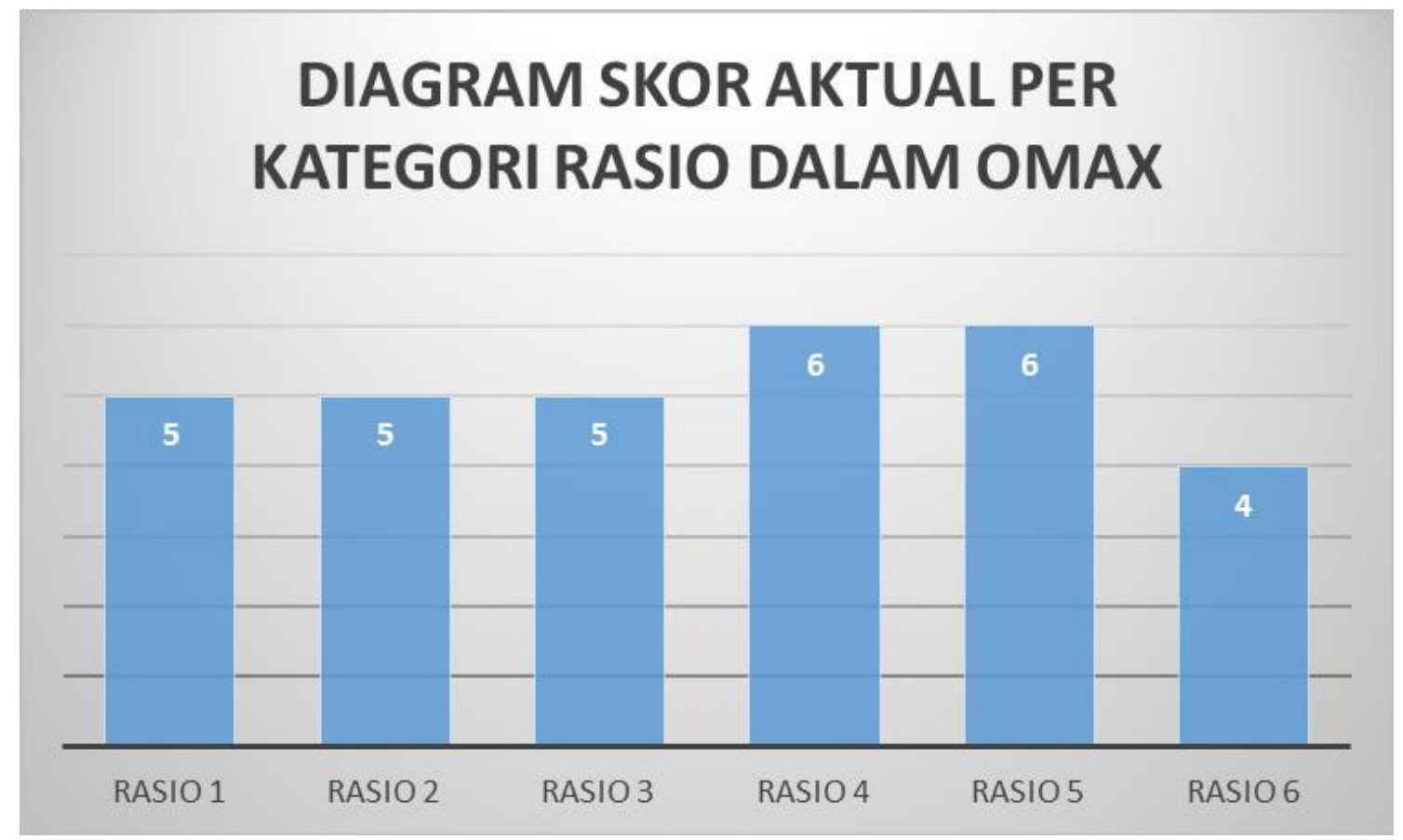

Gambar 1. Diagram Skor Aktual Omax

Berdasarkan diagram tersebut. PDAM Bandarmasih memiliki 2 kategori rasio yang mendapat penilaian baik. yaitu rasio 4 dan rasio 5 . Rasio 4 merupakan penilaian dalam bidang efektifitas jam kerja. Hal ini menunjukan bahwa PDAM Bandamasih telah efektif dalam menerapkan sistem jam kerjanya. Rasio 5 merupakan penilaian dalam bidang efektifitas penggunaan daya tenaga listri (kwh). Hal ini menunjukan bahwa PDAM Bandamasih telah efektif dalam memanfatkan daya listrik yang digunakan untuk proses kegiatan pengolahan. Untuk kategori rasio 1. 2. 3 dan 6. mendapatkan penilaian sedang. Hal ini menunjukkan secara umum. PDAM Bandarmasih telah melakukan kegiatan produksinya secara efektif.

\section{KESIMPULAN DAN SARAN}

\section{Kesimpulan}

Hasil perhitungan kinerja dalam Perusahaan Daerah Air Minum (PDAM) Bandarmasih khususnya dibagian produksi Instalasi Pengolahan Air I dengan menggunakan metode Objektive Matrix(OMAX) bahwa produktivitas total (overall productivity) adalah 499. Dari nilai tersebut secara umum sudah cukup baik meskipun ada beberapa rasio yang masih rendah atau sedang. Sehingga perlu untuk dilakukan improvement (perbaikan) untuk mencapai standar produktivitas kinerja dibagian produksi khususnya pada rasio 1. rasio 2. rasio 3. dan rasio 6 .

\section{Saran}

Beberapa saran atau usulan kepada pihak Perusahaan Daerah Air Minum (PDAM) pada bagian produksi Instalasi Pengolahan Air I untuk dapat dilakukan suatu perbaikan dalam upaya meningkatkan produktivitas kinerja menjadi lebih baik lagi terutama di kategori rasio 1.2.3. dan 6 yang masih mendapat penilaian sedang. Beberapa hal yang dapat dilakukan antara lain :

1. Memperbaiki sistem kerja pada bagian produksi Instalasi Pengolahan Air I dan strategi perusahaan baik dari segi kinerja karyawan. bahan baku utama. serta penggunaan sumber daya yang ada.

2. Mengontrol jumlah Produk yang akan diproduksi. sesuai dengan keadaan tenaga kerja dan mesin produksi.

3. Dalam melakukan usaha peningkatan kinerja pada produksi Instalasi Pengolahan Air (IPA I). perhatikan lagi dalam proses perencanaan akan penggunaan bahan baku utama. bahan baku pendukung serta tingkatkan lagi pengawasan proses kerja dalam melakukan produksi Instalasi Pengolahan Air I (IPA I). 


\section{DAFTAR PUSTAKA}

[1] Amstrong. Michael. 1990. Manajemen Sumber Daya Manusia. Jakarta: PT. Transito Asri Media.

[2] Anwar Prabu Mangkunegara. (2001). Manajemen sumber daya manusia perusahaan. Bandung : Remaja Rosdakarya.

[3] Wibowo, 2010. Manajemen kinerja. Jakarta: Rajawali pers.

[4] Muhammad Bahrudin. 2017. Pengukuran Produktifitas kerja pada bagian produksi dengan menggunakan metode objective matrix (OMAX) dan Root cause analyze (RCA) pada Cv. X

[5] Prima Fithri. 2014. Analisis produktifitas menggunakan metode objective matrix (OMAX) (studi kasus: PT Moron Berlian Sakti).

[6] Hersey. P.. \& Blanchard. K. H. (1993). Management of organizational behavior: Utilizing human resources (6th ed.). Prentice-Hall. Inc.
[7] Cushway. 2004.

http://repository.utu.ac.id/348/1/BAB\%20I_V.pdf

[8] PramudyaPratamaPutra,Mahendra.2007.https://id.12 3dok.com/document/4yr4jk8q-peningkatanproduktivitas-aktivitas-reparasi-pembinaan-jakartamenggunakan-objective.html? tab $=p d f(15$ juni 2020).

[9] Meija.dkk.2004.https://samianstats.files.wordpress.c om/2008/08/penilaiankinerj.pdf (15 Juni 2020)

[10] Ruky. 2001. http://repository.utu.ac.id/348/1/BAB\%20I_V.pdf

[11] Wiradi. 2002.http://kpa.or.id/publikasi/download/de25f-gwrmetodologi-studi-agraria.pdf 
